\title{
Single nucleotide polymorphism analysis of exons 3 and 4 of IGF-1 gene in pigs
}

\author{
L.L. Hao ${ }^{1 *}$, H. Yu ${ }^{1 *}$, Y. Zhang ${ }^{1}$, S.C. Sun ${ }^{3}$, S.C. Liu' ${ }^{1}$, Y.Z. Zeng ${ }^{4}$, Y.X. Ai ${ }^{1}$ \\ and H.Z. Jiang ${ }^{2}$ \\ ${ }^{1}$ College of Animal Science and Veterinary Medicine, \\ Jilin University, Changchun, China \\ ${ }^{2}$ College of Animal Science and Technology, \\ Jilin Agricultural University, Changchun, China \\ ${ }^{3}$ College of Biology, University of Camerino, Camerino, Italy \\ ${ }^{4}$ College of Animal Science and Technology, Yunnan Agricultural University, \\ Kunming, China \\ *These authors contributed equally to this study. \\ Corresponding author: Y.X. Ai or H.Z. Jiang \\ E-mail: aiyx@jlu.edu.cn / jianghz6806@126.com
}

Genet. Mol. Res. 10 (3): 1689-1695 (2011)

Received February 14, 2011

Accepted May 13, 2011

Published August 16, 2011

DOI http://dx.doi.org/10.4238/vol10-3gmr1328

\begin{abstract}
The IGF-1 gene has been implicated as a candidate gene for the regulation of pig growth traits. We analyzed exons 3 and 4 of IGF-1 gene polymorphisms of the Banna mini-pig (28), the Tibetan mini-pig (30), the Junmu pig (55), and L. Yorkshire species (50) using PCR-SSCP. Three genotypes in exon 3 and 6 genotypes in exon 4 were observed, among which, one single nucleotide polymorphism, G201A, on exon 3 and two single nucleotide polymorphisms, A440G and T455C, on exon 4 were found. Statistical analysis of genotype frequencies revealed that the A allele was dominant in the large pig at the G201A locus ( $\mathrm{PIC}=0.20-0.34)$, and the AT alleles were dominant in the large pig at the $\mathrm{A} 440 \mathrm{G}$ and $\mathrm{T} 455 \mathrm{C}$ loci $(\mathrm{PIC}=0.30-0.60)$. The genotype distribution between the various groups was significantly different $(\mathrm{P}$ $<0.01$ ), with the highest heterozygosity seen in Junmu pigs at 0.223 and the lowest seen in L. Yorkshire at 0.098. The genetic distance of the
\end{abstract}


Junmu pig from the L. Yorkshire is the smallest, the distance from the Tibetan miniature pigs is larger, and the distance from the Banna minipig is the largest. The IGF-1 gene polymorphism and heterozygosity results from various pig breeds indicate that IGF-1 is substantially polymorphic with significant difference of the polymorphic distribution and expression levels among various pig breeds. This information provides a theoretical basis for the genetic background of miniature pigs but also provides means to breed improved pig varieties.

Key words: IGF-1; PCR-SSCP; SNP

\section{INTRODUCTION}

Insulin-like growth factor-1 (IGF-1) is important for regulating animal body growth, development and metabolism. The porcine IGF-1 gene is located on chromosome 5 region q23-24 (Wintero et al., 1994). The IGF-1 gene has been implicated as a candidate gene in the regulation of pig growth traits (Suzuki et al., 2004). Even though the mechanisms of human Laro-type dwarfism, sex-linked dwarfism in chickens and other dwarfism conditions have been well studied (Godowski et al., 1989), the dwarfism of miniature pigs remains elusive.

Current Chinese mini-pig breeds include the Wuzhishan, Guizhou xiang, Guangxi Bama, Tibetan, and Banna (Wang et al., 2009). Banna mini-pigs are small, slow growing and display well-balanced development of all parts of the body. They are widely distributed in China and have unique properties. The Tibetan mini-pig is a unique, local, Chinese variety that can adapt to high altitude environments and is one of the lightest Chinese miniature pig breeds. These pigs exhibit strong adaptability and resistance, thin skin, high meat cutability, extra-fine muscle fibers, more intramuscular fat, tasty meat, strong wild flavor, and slow growth.

Miniature pig breeding has been partially hindered by a paucity of studies regarding functional genes associated with growth and development. The Banna and Tibetan miniature pigs are valuable and rare Chinese species that play a unique role in studying new lines of pig breeds. Using polymerase chain reaction-single-strand conformation polymorphism (PCRSSCP), we analyzed IGF-1 polymorphisms in Banna mini-pigs, Tibetan mini-pigs, Junmu pigs, and L. Yorkshire pigs to further explore the effects of IGF-1 on the mechanisms that define the body shape of miniature pigs. The gene structure presented in this study provides a reference for breeding good pig varieties and contributes to the understanding of the mechanisms that regulate development and promote growth; moreover, our results provide a theoretical basis for the genetic background of miniature pigs.

\section{MATERIAL AND METHODS}

\section{Animals}

Animal experiments were performed in accordance with the guidelines on animal care and use established by the Jilin University Animal Care and Use Committee. Twenty-eight tissue samples from the Banna mini-pig (College of Animal Science and Technology, Yunnan Agricultural University, Kunming), 30 from the Tibetan mini-pig (Animal Breeding Center 
in Dahanji village, Zhoukoudian town, Fangshan district, Beijing), 55 from the Junmu pig (Swine Breeding Farm, College of Animal Science and Veterinary Medicine, Jilin University, Changchun) and 50 from the L. Yorkshire (Swine Breeding Farm, College of Animal Science and Veterinary Medicine, Jilin University, Changchun) were randomly collected, placed in a centrifuge tube containing $70 \%$ alcohol, and transported to the laboratory in an ice box. Genomic DNA was extracted using a Beijing Tiangen genomic DNA extraction kit. The purity and concentration of the DNA samples were confirmed with agarose gel electrophoresis and ultraviolet spectrophotometry, and the samples were diluted to $100 \mathrm{ng} / \mu \mathrm{L}$ and stored at $-20^{\circ} \mathrm{C}$.

\section{Amplification of the IGF-1 gene by PCR-SSCP}

PCR-SSCP primers directed toward exons 3 and 4 of IGF-1 (GI: 164473) were designed using the Primer5.0 software (Table 1). Primers were synthesized by the Shanghai Sangon Biological Engineering Technology Engineering Service Co., Ltd. PCR-SSCP reactions of $25 \mu \mathrm{L}$ included $2.5 \mu \mathrm{L}$ 10X Ex Taq buffer $\left(\mathrm{Mg}^{2+}\right.$ free), $2 \mu \mathrm{L} 2.5 \mathrm{mM}$ dNTPs, $1 \mu \mathrm{L} 10 \mathrm{pM}$ upstream and downstream primers, $1.3 \mu \mathrm{L} 25 \mathrm{ng} / \mu \mathrm{L}$ template DNA, $0.2 \mu \mathrm{L} 5 \mathrm{U} / \mu \mathrm{L}$ Ex Taq Polymerase (TakaRa), and $17 \mu \mathrm{L}$ ultra-pure water. PCRs were performed under the following conditions: a 3-min hot start at $95^{\circ} \mathrm{C}, 30$ cycles of denaturation for $45 \mathrm{~s}$ at $94^{\circ} \mathrm{C}$, annealing for $45 \mathrm{~s}$ and extension for $1 \mathrm{~min}$ at $72^{\circ} \mathrm{C}$, and a final 8 -min extension at $72^{\circ} \mathrm{C}$. Products were loaded onto a $1 \%$ agarose gel, resolved by gel electrophoresis, and visualized by a gel imaging system.

\begin{tabular}{lcl}
\multicolumn{2}{c}{ Table 1. Primer sequences for exons 3 and 4 of IGF-1 gene. } \\
\begin{tabular}{lcl}
\hline Gene location & Product size & Primer sequence \\
\hline Exon 3 & 432 bp & F: 5'-ACGAATGTGGCACTGACTG-3' \\
Exon 4 & 459 bp & R: 5'-CTCTTGAGGATGGCTGACC-3' \\
& & F: 5'-GCCCATCCACTTACATTGAC-3' \\
\end{tabular}
\end{tabular}

\section{SSCP analysis and sequencing}

One microliter PCR products was mixed with $5 \mu \mathrm{L}$ loading buffer, denatured at $98^{\circ} \mathrm{C}$ for $10 \mathrm{~min}$, and placed in an ice bath for $5 \mathrm{~min}$ to maintain a denatured state. The denatured PCR products were loaded onto a $12 \%$ non-denaturing polyacrylamide gel, resolved by electrophoresis (Acr:Bis; 29:1) at $10 \mathrm{~V} / \mathrm{cm}$ for 10-11 h, and visualized with silver staining. Samples of different genotypes were sequenced by the Shanghai Sangon Biological Engineering Technology Engineering Service Co., Ltd.

\section{Data analysis}

PCR-SSCP polymorphism results were corrected and analyzed using DNAMAN5.5.5, BioEdit7.0.5, Chromas2.2.3 and other biological software by searching single nucleotide polymorphism (SNP) sites and identifying composite genotypes. The SNP loci, heterozygosity, and genotype and allele frequencies were predicted for the two exons using the Popgene32 software; moreover, polymorphic information content (PIC) was determined using the PIC_ Calc 0.6 software. 


\section{RESULTS}

\section{PCR-SSCP results}

IGF-1 gene fragments, 432 bp (exon 3) and 459 bp (exon 4), were amplified by PCR and resolved by gel electrophoresis (Figure 1). The two IGF-1 gene fragments from the four pig varieties were analyzed under non-denaturing gel electrophoresis conditions. Three genotypes in exon 3 and 6 genotypes in exon 4 were observed.

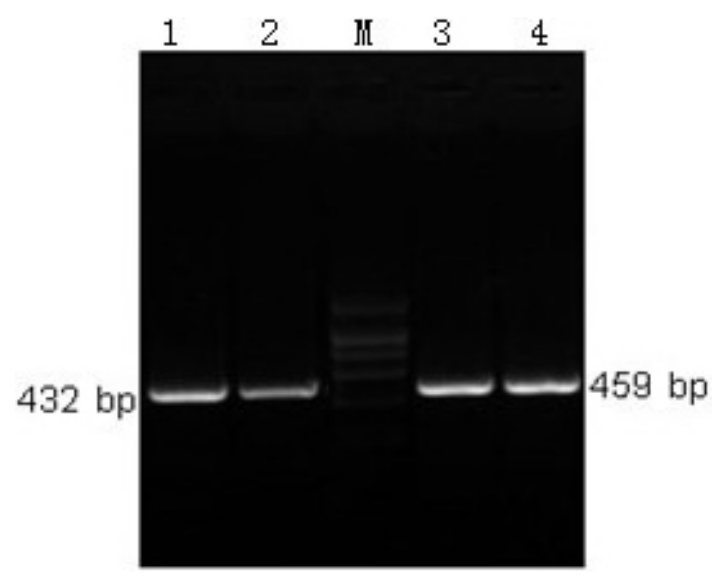

Figure 1. PCR results of exons 3 and 4 of IGF-1 gene. Lanes 1, $2=$ PCR results of exon 3 of IGF-1. Lanes 3, $4=$ PCR results of exon 4 of IGF-1. Lane $M=$ DL2000 DNA marker.

\section{Sequence analysis and SNP loci screening}

DNA samples from different genotypes were sequenced. The sequences were corrected using Chromas 2.2.3 and BioEdit 7.0.5 softwares and compared and analyzed with the DNAMAN5.2.2 biological software. Three SNP loci, G201A (exon 3), A440G and T455C (exon 4) were found in IGF-1 gene fragments.

\section{Statistical analysis of the IGF-1 gene and its genotype frequencies}

Genotype frequencies in exons 3 and 4 were statistically analyzed (Tables 2 and 3), and their variation distribution was tested in different pig breeds (Tables 4 and 5). Tables 2-6 show that, for the G201A locus in IGF-1 exon 3, B (A base) was the dominant allele in large pigs. PIC was between 0.20 and 0.34 , and the genotype distribution between the various groups was significantly different $(\mathrm{P}<0.01)$. Analysis of the combination genotype of the two loci A440G and T455C in IGF-1 exon 4 indicated that C (AT) was the dominant allele in large pigs, wherein PIC was between 0.30 and 0.60 . In contrast, there are no uniform general characteristics for these two sites in miniature pigs. The genotype distribution between the various groups was significantly different $(\mathrm{P}<0.01)$, with the highest heterozygosity seen in Junmu pigs at 0.223 and the lowest seen in L. Yorkshire at 0.098 . 
Table 2. Genotype and allele frequency of IGF-1 exon 3 in different pig breeds.

\begin{tabular}{|c|c|c|c|c|c|c|c|}
\hline \multirow[t]{2}{*}{ Breed } & \multirow[t]{2}{*}{ Number } & \multicolumn{3}{|c|}{ Genotype frequency } & \multicolumn{2}{|c|}{ Allele frequency } & \multirow[t]{2}{*}{ PIC } \\
\hline & & $\mathrm{AA}$ & $\mathrm{AB}$ & BB & A & B & \\
\hline B & 28 & 0 & 0.75 & 0.25 & 0.375 & 0.625 & 0.305 \\
\hline Z & 30 & 0.87 & 0 & 0.13 & 0.870 & 0.130 & 0.201 \\
\hline $\mathrm{J}$ & 55 & 0 & 0.30 & 0.70 & 0.150 & 0.850 & 0.332 \\
\hline D & 50 & 0 & 0.15 & 0.85 & 0.075 & 0.925 & 0.222 \\
\hline
\end{tabular}

$\mathrm{B}=$ Banna mini-pig; $\mathrm{Z}=$ Tibetan mini-pig; $\mathrm{J}=$ Junmu pig; $\mathrm{D}=\mathrm{L}$. Yorkshire pig; $\mathrm{PIC}=$ polymorphism information content.

Table 3. Genotype and allele frequency of IGF-1 exon 4 in different pig breeds.

\begin{tabular}{|c|c|c|c|c|c|c|c|c|c|c|c|c|}
\hline \multirow[t]{2}{*}{ Breed } & \multirow[t]{2}{*}{ Number } & \multicolumn{6}{|c|}{ Genotype frequency } & \multicolumn{4}{|c|}{ Allele frequency } & \multirow[t]{2}{*}{ PIC } \\
\hline & & $\mathrm{CC}$ & $\mathrm{DD}$ & $\mathrm{EE}$ & $\mathrm{FF}$ & $\mathrm{CF}$ & $\overline{\mathrm{DE}}$ & $\mathrm{C}$ & $\mathrm{D}$ & $\mathrm{E}$ & $\mathrm{F}$ & \\
\hline B & 28 & 0 & 0.50 & 0 & 0.25 & 0.25 & 0 & 0.125 & 0.500 & 0 & 0.375 & 0.555 \\
\hline Z & 30 & 0.75 & 0 & 0 & 0 & 0.25 & 0 & 0.875 & 0 & 0 & 0.125 & 0.305 \\
\hline $\mathrm{J}$ & 55 & 0.50 & 0.05 & 0 & 0 & 0.25 & 0.20 & 0.625 & 0.150 & 0.100 & 0.125 & 0.587 \\
\hline D & 50 & 0.65 & 0.05 & 0.10 & 0 & 0.10 & 0.10 & 0.700 & 0.100 & 0.150 & 0.050 & 0.517 \\
\hline
\end{tabular}

$\mathrm{B}=$ Banna mini-pig; $\mathrm{Z}=$ Tibetan mini-pig; $\mathrm{J}=$ Junmu pig; $\mathrm{D}=\mathrm{L}$. Yorkshire pig; $\mathrm{PIC}=$ polymorphism information content.

\section{Table 4. The distribution of IGF-1 exon 3 gene analyzed by the $\chi^{2}$ test of independence.}

\begin{tabular}{|c|c|c|c|c|}
\hline Breed & B & $\mathrm{Z}$ & $\mathrm{J}$ & D \\
\hline $\begin{array}{l}\mathrm{B} \\
\mathrm{Z} \\
\mathrm{J} \\
\mathrm{D}\end{array}$ & & 29.894 & $\begin{array}{c}9.649^{*} \\
127.684\end{array}$ & $\begin{array}{r}24.754 \\
169.220 \\
4.908\end{array}$ \\
\hline
\end{tabular}

*Significant difference between groups $\left(\mathrm{P}<0.01, \chi_{1}^{2}(0.01)(\mathrm{d} . \mathrm{f} .=1)=6.635\right)$. For breed abbreviations, see legend to Table 2.

Table 5. The distribution of IGF-1 exon 4 gene analyzed by the $\chi^{2}$ test of independence.
\begin{tabular}{lcccc}
\hline Breed & B & Z & D \\
\hline B & $69.667^{*}$ & $45.076^{*}$ & $69.881^{*}$ \\
Z & & $25.128^{*}$ & $26.833^{*}$ \\
J & & 11.278 \\
D & & \\
\hline
\end{tabular}

*Significant difference between groups $\left(\mathrm{P}<0.01, \chi_{1}{ }_{1}(0.01)(\right.$ d.f. $\left.=1)=6.635\right)$. For breed abbreviations, see legend to Table 2 .

\section{Table 6. Genetic diversity of IGF-1 exon 4 in four pig breeds.}

\begin{tabular}{|c|c|c|c|c|c|}
\hline Population & Number & A & $\mathrm{Ae}$ & $H_{O}$ & $H_{E}$ \\
\hline B & 28 & 2.000 & 1.616 & 0.113 & 0.354 \\
\hline Z & 30 & 0.150 & 0.130 & 0.117 & 0.105 \\
\hline $\mathrm{J}$ & 55 & 2.000 & 1.634 & 0.223 & 0.391 \\
\hline D & 50 & 2.000 & 1.486 & 0.098 & 0.325 \\
\hline
\end{tabular}

For breed abbreviations, see legend to Table 2. A = average number of alleles; $\mathrm{Ae}=$ effective number of alleles; $H_{O}$, $H_{E}=$ observed and expected heterozygosity, respectively. 
According to Nei's unbiased phylogenetic tree (Figure 2), the genetic distance of the Junmu pig from the L. Yorkshire is the smallest, the distance from the Tibetan miniature pigs is larger, and the distance from the Banna mini-pig is the largest.

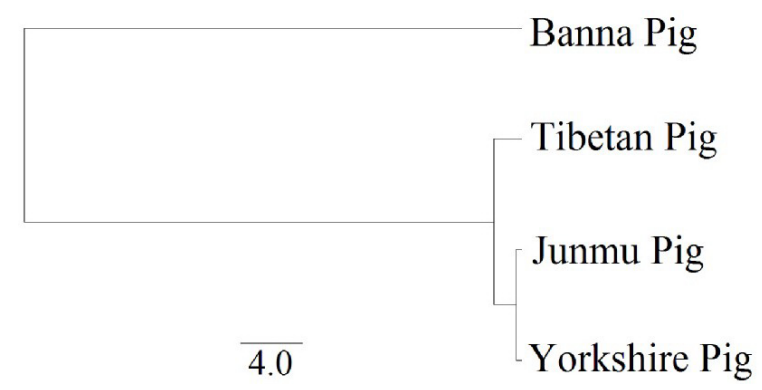

Figure 2. Nei's unbiased genetic distance dendrogram for the four pig breeds.

\section{DISCUSSION}

IGF-1 genotype frequencies of exons 3 and 4 in four pig breeds indicate the presence of one SNP in exon 3 and two SNPs in exon 4, totaling 6 genotypes. All three SNP loci lack heterozygous and combination genotypes because Banna and Tibetan miniature pigs, along with their extensive inbreeding, offer very small sample sizes, which may result in the loss of a genotype. Normally, the amount of samples available for analysis and breeding is very large, so genotypes are consistently represented. The distribution of SNP genotypes in two exons in different pig breeds was analyzed using the chi-square independence test, which demonstrated a significant difference, indicating extensive genetic divergence between Banna, Tibetan, L. Yorkshire, and Junmu pigs. Because the Junmu pigs used in the laboratory have been bred from L. Yorkshire pigs, both derived from European pig breeds by long-term artificial selection, fecundity and meat quality have been stabilized. In contrast, because the Banna and Tibetan mini-pigs are Asian pigs from remote mountainous areas, an environment that promotes close breeding and solitary survival, their genotypes and phenotypes are more stable.

The average PIC is an ideal index to assess gene fragment polymorphisms. A PIC value $>0.5$ indicates a highly polymorphic region; however, $0.25<$ PIC $<0.5$ indicates a moderate polymorphic site. Lastly, a PIC value $<0.25$ signifies a low polymorphism site. The PIC of exon 3 is generally between 0.20 and 0.34 , because it harbors only one SNP. Tibetan miniature pigs and L. Yorkshire pigs exhibit low polymorphism, and Junmu and Banna pigs exhibit moderate polymorphism. Because there are two SNPs in exon 4, its PIC, which is between 0.30 and 0.60 , is higher than for exon 3, reflecting the polymorphism distribution of IGF-1 in different pig breeds. The Tibetan mini-pig exhibits low polymorphism, whereas the other three breeds are highly polymorphic. Genetic heterozygosity indicates the proportion of the group with site heterozygotes at some locus. The average heterozygosity of loci reflects the level of variation of the genetic structure, where variability directly correlates with heterozygosity and the ability to adapt to the environment. Among the four groups, the average observed and expected heterozygosity of Junmu pig populations was higher than that of the other groups, which revealed that the Junmu pig was less inbred than L. Yorkshire, Tibetan and Banna pigs. Nei's unbiased genetic distance dendrogram shows that, for the genotype composition and proportion, L. Yorkshire and Junmu pigs are close enough together 
to be in one class; they are less related to Tibetan miniature pigs, and they are most different from Banna pigs. However, the difference between the Banna and the Tibetan miniature pigs is much larger than the differences between the Tibetan miniature pig and the L. Yorkshire and Junmu pigs.

Using PCR-SSCP, Xue and Xu (2008) analyzed the IGF-1 gene of local Laiwu and Yimeng Black pig breeds in the Shandong Province of China. Three polymorphic genotypes, $\mathrm{AA}, \mathrm{AB}$ and $\mathrm{BB}$, were identified in exon 3. Statistical analysis denoted a significant difference $(\mathrm{P}<0.01)$ between the genotype frequencies of the two pig breeds. Xiao et al. (2007) analyzed the IGF-1 exon 4 in Songliao Black pigs using PCR-SSCP. Different frequency distributions of the two IGF-1 gene alleles and three genotypes were identified; moreover, the genetic polymorphism was higher. $\mathrm{Gu}$ (2007) also detected and confirmed the existence and the genotypes of three point mutations in exons 3 and 4 of IGF-1 by SSCP and sequencing in 8 pig breeds, including the Sichuan Daocheng Tibetan miniature pig, Yanan pig, Changya pig, Dahe pig, Dahe black pig, Yorkshire pig, and others. The same loci were analyzed in this study, and three mutations in IGF-1 exons 3 and 4 were identified, in line with the above results.

The IGF-1 gene polymorphism and heterozygosity results for various pig breeds indicate that IGF-1 is substantially polymorphic, and its distribution and expression levels show significant differences between various pig breeds. These results illustrate significant differences in the dominant genes among miniature pigs and between miniature pigs and large pigs. Further studies are necessary to determine whether the polymorphisms in these coding regions are intrinsically related to the quantitative traits of pork performance, such as body weight, daily weight gain and dressing percentage.

\section{ACKNOWLEDGMENTS}

Research supported by the National Natural Science Foundation (\#30871839) of China.

\section{REFERENCES}

Godowski PJ, Leung DW, Meacham LR, Galgani JP, et al. (1989). Characterization of the human growth hormone receptor gene and demonstration of a partial gene deletion in two patients with Laron-type dwarfism. Proc. Natl. Acad. Sci. U. S. A. 86: 8083-8087.

Gu YR (2007). The Genetic Diversity and Genetic Effects of IGF-1 Gene in Different Pig Breeds. Sichuan Agricultural University, Ya'an.

Suzuki K, Nakagawa M, Katoh K, Kadowaki H, et al. (2004). Genetic correlation between serum insulin-like growth factor-1 concentration and performance and meat quality traits in Duroc pigs. J. Anim. Sci. 82: 994-999.

Wang GH, Yin XM, Sun X and Zhao DM (2009). General situation of miniature pig resources at home and abroad. Chin. J. Comp. Med. 19: 71-73.

Wintero AK, Fredholm M and Andersson L (1994). Assignment of the gene for porcine insulin-like growth factor 1 (IGF1) to chromosome 5 by linkage mapping. Anim. Genet. 25: 37-39.

Xiao SQ, Zhang JB, Li S, Zhao ZH, et al. (2007). The exon4 polymorphism of IGF-I gene and its relationship with partial performances in Songliao black swine. China Anim. Husb. Vet. Med. 34: 55-57.

Xue HL and Xu LX (2008). Genetic polymorphisms and genetic effects of IGF2 gene in pigs. Yi Chuan 30: 179-184. 